\title{
TRAFFIC CONGESTION, RELIABILITY AND LOGISTICAL PERFORMANCE: A MULTI-SECTORAL ASSESSMENT
}

\author{
Alan McKinnon, Julia Edwards, Maja Piecyk and Andrew Palmer \\ Logistics Research Centre \\ Heriot-Watt University,EDINBURGH \\ Email: A.C.McKinnon@hw.ac.uk
}

\begin{abstract}
:
Recent research has updated a 1998 study of the effects of traffic congestion on logistical efficiency in the UK. It has focused on the contribution of congestion to unreliability across nine sectors. The relationship between traffic flow and transit time variability has been modeled using data from the Highways Agency and speed-flow ratios. An analysis of transport KPI survey data and an interview survey of 32 managers in 24 companies have explored the relative importance of congestion, The survey also examined the extent to which companies are adapting their logistical systems to worsening traffic congestion in the UK.
\end{abstract}

Key words: traffic congestion, transit time variability, reliability, logistical efficiency, UK.

\section{Introduction}

Government congestion measurement and investment appraisal models do not adequately assess the effects of congestion-related unreliability. The standard metric used, the average number of seconds delay per vehicle-km, does not take account of the variability of traffic levels and probability of a logistics operation being seriously disrupted. It ignores the consequential effects of late deliveries caused by traffic congestion which can reduce the productivity of warehousing and transport operations and overall service quality.

Research undertaken for the Institute of Logistics (now the CILT) in 1998 examined these wider effects in a survey of seven distribution centres located along congested motorway corridors (McKinnon, 1999). Over the past decade, traffic congestion both in urban areas and on the trunk road network has worsened, while a range of logistical trends has altered companies' exposure to congestion and their ability to accommodate it within their transport and warehousing operations. This paper will present the results of recent research designed to update and extend the earlier study. Given space limitations, it focuses on three issues: the relationship between traffic levels and transit time variability, the relative contribution of congestion to unreliability in logistical scheduling and the methods that companies are using to adapt their logistics operations to worsening congestion.

\section{Methodology}

The new study was divided into three parts. The first reviewed literature published over the past ten years on the links between congestion and logistical reliability. A survey of twenty-five journals and numerous research reports revealed several new studies (e.g. Winston and Shirley, 2004; Cambridge Systematics Inc., 2004; Sankaran, Gore, and Coldwell, 2005; Kuipers and Rozemeijer, 2006; Wilson, 2007) but only limited advances in our monitoring and understanding of the impact of congestion on logistics. Road freight $\mathrm{KPI}$ surveys commissioned by the UK government proved a valuable source of cross-sectoral and timeseries data on the relative importance of congestion as a source of unreliability. All the relevant data can be downloaded from the Freight Best Practice Programme website: www.freightbestpractice.org.uk

The second part used data provided by the UK Highways Agency on volumes of traffic flow, congestion incidents and their causes to model the probability of transport delays of varying degrees of severity occurring over different distance ranges. This defined the relationship between the level of traffic flow on different classes of trunk road and transit time variance for freight vehicles.

The third part comprised an interview survey of 32 senior logistics managers in 24 companies, including nine logistics service providers and a mix of producers and distributors in nine sectors: grocery, alcoholic beverage, steel, construction, paper, chemicals, forest products, automotive and electronics. The aim of this survey was to assess the effects of congestion on transport and warehousing operations, the provision of 
additional resources to accommodate congestion and the inter-relationship between congestion and other sources of unreliability in supply chains.

\section{Relationship between Traffic Volumes and Transit Time Variability}

Traffic flow data provided by the Highways Agency was used to assess the minimum and maximum transit times for a sample of routes of variable length. Means and standard deviation values were calculated for hourly traffic flows on an average weekday (excluding public holidays) at 4500 count points across the trunk road network. By applying an appropriate speed-flow formula it was possible to convert the traffic volumes into estimates the average speed on each link. This made it possible to derive travel times for each link in the network.

A sample of 21 lorry journeys was extracted from the government's main annual survey of road freight movement (the Continuing Survey of Road Goods Transport (CSRGT) which in 2007 covered 140,000 journeys. A shortest path algorithm was used to determine the quickest routes for each of the 21 journeys using the average traffic volumes and speed-flow formulae. The route lengths ranged from $7 \mathrm{~km}$ with 11 road links to $773 \mathrm{~km}$ with 188 links. A series of 100 simulations were run for each of the 21 routes. These simulations applied a random traffic volume to each link in the route within a range of two standard deviations on either side of the mean flow (this equates to approximately a 95\% confidence interval).

The results show that transit time variability in absolute terms, measured in minutes, increases with the length of the route. In relative terms, expressing the variability as a percentage of the average arrival time, the opposite is the case. The greatest percentage differences are observed on the shortest routes. For example on routes of 7,32 and $47 \mathrm{kms}$ the differences between shortest and longest transit times were, respectively, $14 \%, 19 \%$ and $18 \%$. For routes of 259,455 and $773 \mathrm{kms}$ the corresponding values were, respectively, $5 \%, 7 \%$ and $4 \%$. Clearly, over greater distances, a vehicle has greater opportunity to make up time lost on the more congested stretches of the route. Figure 1 plots the maximum and minimum trip times against route length, with each of the 21 routes shown as a point on the graph. The correlations between the earliest and latest arrival times and distance traveled are reasonably strong at 0.92 and 0.88 respectively. The results of this type of analysis could be factored into companies' logistics modeling to ensure that allowance is made for worsening traffic in the strategic planning of logistics systems.

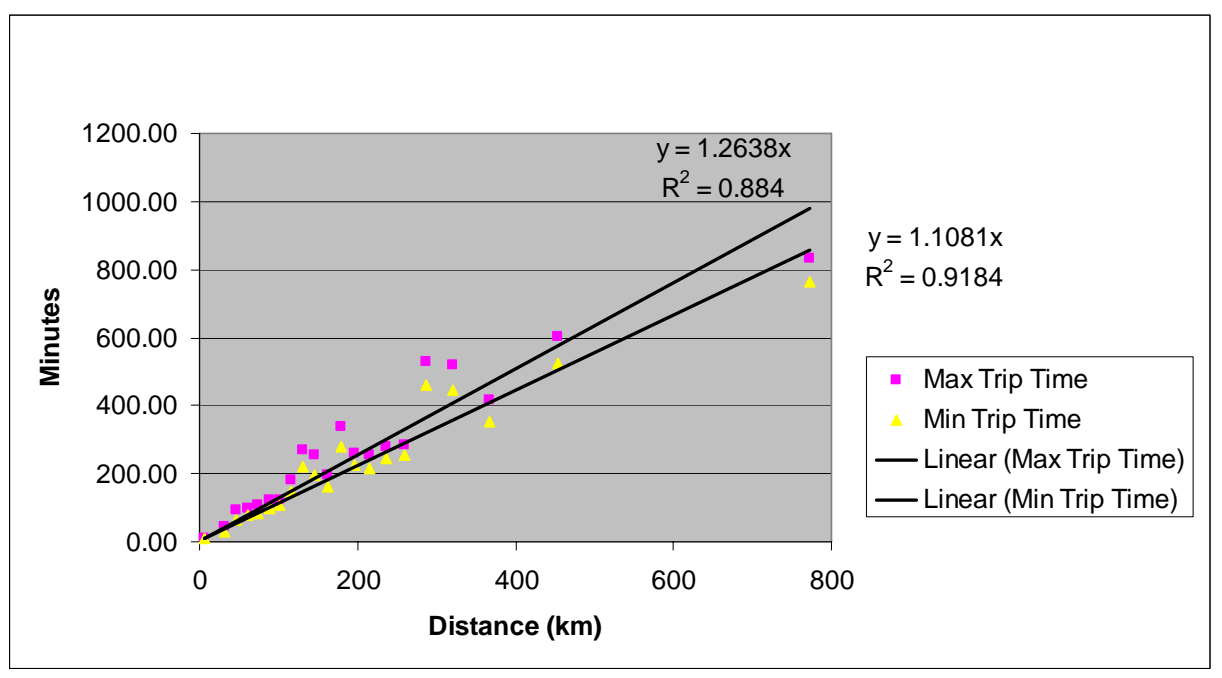

Figure 1: Relationship between maximum and minimum transit times over varying distances

\section{Relative Importance of Congestion as a Source of Unreliability}

Previous research has established that traffic congestion is only one of many factors that disturb logistical schedules. These other factors can be broadly divided into two categories: (i) factors directly related to the transport operation (ii) factors affecting other aspects of the logistics activity. Information on the former category has been collected over the past decade in the UK government's Transport KPI surveys, while the recent interview survey has provided new insights into the latter category. 


\section{(i) Analysis of Transport KPI Survey Data}

Since 1997 the UK government has commissioned eleven key performance measurement (KPI) surveys of road freight operations across eight sectors. These surveys take the form of 'synchronised audits' in which large numbers of vehicle fleets are simultaneously measured against a standard set of criteria over a 24-48 hour period (McKinnon and Ge, 2004). One of the key criteria is 'deviations from schedule'. This data has been recorded for KPI surveys in seven sectors: food, drink, automotive, non-food retailing, express parcels, pallet-load networks and builders merchants.. In the case of food products, three surveys have been undertaken, in 1998, 2002 and 2007, making it possible to conduct a time-series analysis for this sector. It has also been possible to separate food retailers from food suppliers in the case of the 2002 survey.

Across the seven sectors surveyed since 2002 , data is available on 55,820 journey legs. $26 \%$ of these legs were subject to a delay and $35 \%$ of these delays (i.e. $9 \%$ of the total) were attributed mainly to traffic congestion. The incidence of delays varied widely among the sectors (Figure 2). In the express parcels sector, where a premium is attached to rapid and reliable delivery, no delays were reported. At the other extreme, $44 \%$ of the trunk movement of pallets between local collection / delivery depots and the central hubs were delayed, though only $14 \%$ of these delays were blamed on congestion. The local collection / delivery of pallet-loads, food retailers and automotive companies also experienced a relatively high frequency of delays with congestion accounting for $30-34 \%$ of the total.

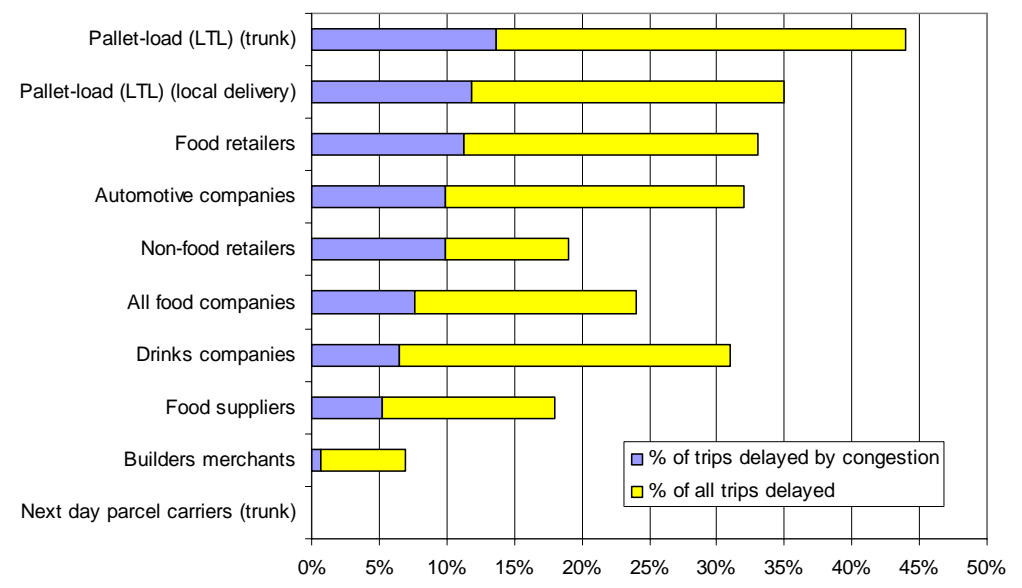

Figure 2 : Sectoral variation in the frequency of total and congestion-related delays

The average length of the delay caused by traffic congestion was relatively short. It averaged 24 minutes, by comparison with an unweighted average delay time for all causes of 41 minutes. When the frequency and duration of delays are combined and the results weighted by the number of journey legs surveyed in each of the sectors, 'own company actions' emerges as the most important source of delays accounting for $31 \%$ of the total, followed by problems at delivery points $(28 \%)$. Traffic congestion came third, being responsible for $23 \%$ of total delay time.

A time-series analysis of KPI data for the food sector revealed that traffic congestion's share of total delays, their average duration and overall contribution to delay time remained fairly constant between 1998 and 2007. Its share of total delay time in the food supply chain rose only slightly from $20 \%$ to $22 \%$ over the period.

These transport KPI survey results require two qualifications. First, as companies will already have allowed for congestion-related delays in their scheduling, the figures are likely to under-estimate the true magnitude of the congestion problem. Second, the various causes of schedule deviations are inter-related. For example, a vehicle delayed by congestion may miss its booking-in slot at a distribution centre and have to wait until the next available off-loading slot. If it is making multiple deliveries, delays will then accumulate, being amplified by the booking-in systems at each customer location. 


\section{(ii) Analysis of the Interview Data}

Only around a quarter of the managers interviewed considered traffic congestion to be the most important of source of unreliability in their logistics operations. In the course of the interviews managers were asked unprompted about the other factors disrupting logistical schedules. Figure 3 summarises the responses from managers in twenty-two companies. The three most important factors were deemed to be vehicle $/$ equipment break-downs, staffing problems and delays in the production operation, each accounting for $16 \%$ of all the factors mentioned. Deficiencies in the planning process and poor forecasting, each accounting for $9 \%$ of mentions, are inter-related. The key to successful logistics management lies in managing variability in the levels and pattern of demand from day to day.

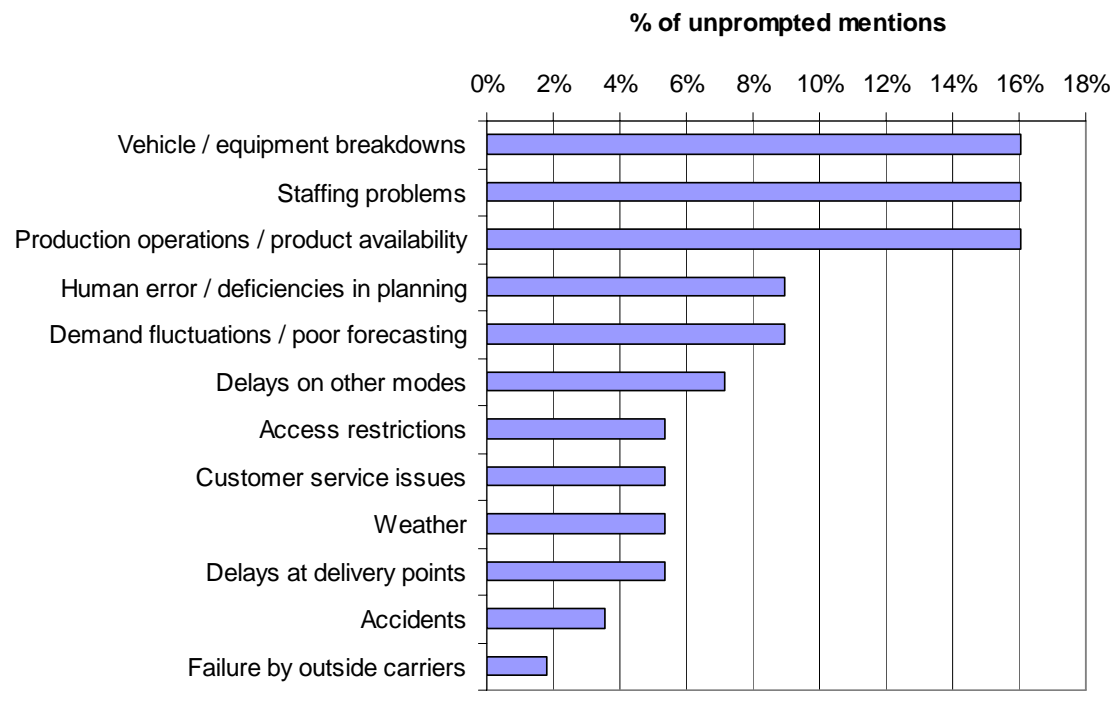

Figure 3: Factors, other than congestion, affecting delivery reliability

\section{Adaptation of Logistics Systems to Congested Infrastructure}

During the course of the interviews companies were asked if they had applied any of a list of congestion mitigation measures or were planning to implement them. Interviewees were also given the opportunity to mention other congestion-related initiatives that they had undertaken. The broadening of the range of sectors surveyed revealed new methods of adaptation that were not applied by the FMCG companies investigated in 1998. Attention will focus here on measures related to transport, warehousing and inventory.

\section{(i) Transport}

Increase fleet size: This can take two forms:

(a) Increase the number of powered units (i.e. rigid vehicles or tractor units): the majority of the companies interviewed argued that there had been little or no increase in the number of vehicles as a result of congestion. With more careful planning of the delivery operation or some of the other adaptation measures listed below they had minimised the effect of congestion on vehicle numbers.

(b) Increase in the ratio of trailers to tractors (i.e. the 'articulation ratio'): where the ratio is greater than one, companies can effectively decouple the transport operation from loading / unloading activities. These activities can then proceed even if inbound vehicles are delayed. Most companies reported a marginal reduction in the ratio of tractors to trailers in recent years, presenting this as evidence of improved transport efficiency. The few companies that had seen their articulation ratios increase attributed this mainly to factors other than congestion, though most conceded that it made it easier to accommodate traffic delays.

Adjustments to journey planning: Computerised vehicle routeing software which is now widely used across UK industry incorporates average speeds for different classes of roads. Any reduction in these average speeds would be an obvious indicator of the impact of congestion on delivery operations. The main application of this software is for multiple drop / collection operations. Only three of the companies (9\%) which used it for this purpose claimed to have revised average speeds downwards in recent years. 
Rescheduling of deliveries to off-peak periods: A distinction can be made between the rescheduling of day-time deliveries to avoid the morning and afternoon peaks and the rescheduling of deliveries into the evening and night. Where possible most companies try to avoid delivering at peak times, but this is often constrained by site access, customer requirements, train and ferry timetables etc. According to government statistics, the proportion of truck-kms run between 8pm and 6am in the UK has more than doubled over the past twenty years. Roughly half the companies consulted had increased night-time running over the past 5-10 years. This switch is only partly motivated by a desire to avoid congestion, however. It is also done to improve the utilisation of vehicle assets and to meet the growing demand for overnight delivery in the express parcels and pallet-load sectors. A large steel distributor had raised its proportion of night-time running from $20 \%$ to $50 \%$ over the past ten years. $50 \%$ was considered the maximum because vehicles were run around 20 hours per day and need balanced scheduling between day and night. Some companies incentivised customers to receive supplies through the night by offering discounted delivery rates.

Altering working practices: It had been predicted that the imposition of the Working Time Directive in April 2006 would make it harder for companies to reschedule delivery operations to accommodate worsening traffic congestion. The responses of interviewees suggests that this has not been the case. The definition of 'periods of availability' that the UK government adopted has given companies greater flexibility than expected and companies have found ways of reorganising work schedules to accommodate the new regulations. As one logistics manager explained, the WTD has forced companies to be more 'creative' in the way in which they allocate tasks and manage their staff.

\section{(ii) Inventory}

As in the 1998 study, there was almost unanimous agreement among the managers interviewed that traffic congestion was not affecting inventory levels within their logistics operations. A simple calculation based on macro-level government statistics can explain this response. According to UK government statistics (Dept for Transport, 2007) there was an average of 4.4 weeks of inventory in the manufacturing, wholesaling and retailing sectors in 2005. The average length of haul for all domestic freight movements by all modes in the UK is $140 \mathrm{kms}$. If one assumes that these movements run at an average speed of $70 \mathrm{kms}$ per hour and allow an hour for loading and unloading at either end of the journey, the average transit time will be only 4 hours. Even on the $10 \%$ of journeys most seriously delayed on the strategic road network, the average delay during the morning peak is only 26.6 minutes (Dept. for Transport, 2007). Mean transit times and congestion delays are, therefore, extremely short relative to the average amount of time that products spend in the supply chain.

\section{(iii) Warehousing}

The survey found little evidence of warehouse design and management being significantly influenced by worsening traffic congestion:

Warehouse design: The main design characteristics relevant to congestion are the configuration of the cross-docking area and the separation of loading and off-loading bays. As cross-docking is the most timesensitive activity in a warehouse, the internal layout needs to designed in a way that maximizes the speed of this operation. Companies with separate loading and off-loading bays were better able to cope with inbound delays, though congestion had been a minor consideration in incorporating this design feature.

Internal warehouse operating system: Building more slack into internal handling systems should enhance the flexibility of warehousing operations and thus improve their ability to cope with congestion-related delays. If congestion were having a major impact on warehouse performance, therefore, one might expect to see companies investing in additional handling equipment. The survey, like that in 1998 , detected little evidence of this.

Warehouse space requirement: One determinant of a DC's ability to cope with unreliability in the delivery system is the amount of space available. In the 1998 study, two of the seven DC visited were spaceconstrained and this reduced their ability to divert staff and equipment away from the less time-sensitive 'put-away' operation (i.e. putting goods for storage into the racking) to much more time-sensitive crossdocking and picking operations. They simply did not have enough space to accommodate a build-up of inbound supplies awaiting put-away. The unanimous response of the managers surveyed in 2007, including those at one of the two DCs with a space problem in 1998, was that, when considering their response to traffic congestion, warehouse space was not an issue. 
Number of DCs: Some commentators have speculated that if road congestion in the UK gets much worse, the process of warehouse centralisation may go into reverse as companies find it increasingly difficult to service customers within the required lead times from their existing DCs. The study found some examples of companies planning to decentralize their operations partly because of traffic congestion. Several other producers of industrial commodities which have centralized their production over the past 15-20 years are also finding it hard to serve peripheral areas directly from their factories as a result of congestion. Initially they are planning to develop 'out-bases' for vehicles and drivers to ensure longer deliveries can be made within the drivers' hours regulations on more congested roads.

Location of DCs: None of the companies consulted had plans to relocate DCs because of congestion at local, regional or national levels.

\section{Conclusions}

A series of government-sponsored transport KPI surveys suggest that approximately a quarter of road freight journeys are subject to a delay and that traffic congestion accounts for roughly a third of these delays. Other factors, such as equipment breakdowns, poor production planning and staffing problems, can occur more frequently and cause longer average delays. When account is taken of the average duration of different types of delay, it is found that congestion is responsible for roughly $23 \%$ of total delay time in road freight transport. Only a quarter of a sample of 32 logistics managers regarded traffic congestion as the main source of unreliability. There is, however, a complex interaction between congestion and other causes of schedule deviations. The limited amount of time-series data available (from the food supply chain) indicates that the proportion of deliveries delayed by congestion increased only marginally between 2002 and 2007. It would be wrong to generalise on this result, however, as there are significant differences in the absolute and relative importance of congestion-related delays in different sectors. Individual companies have also reported that the reliability of their logistics operations has been markedly deteriorating in recent years mainly as a result of traffic congestion.

The interview survey, across nine sectors, found little evidence of traffic congestion causing companies to restructure their logistical systems or modify key aspects of their transport and warehousing operations. Fleet sizes, tractor-trailer articulation ratios, the speed calibration of vehicle routing software, inventory levels and internal warehouse design, for example, were largely unaffected. There had, however, been a growth of evening / night-time delivery and greater use of regional depots and outbased vehicles / drivers. Overall, companies have been able to adapt their logistics operations to traffic congestion gradually over a long period and minimising its impact on reliability and efficiency has become a core management skill.

\section{References}

- Cambridge Systematics Inc. (2004), Traffic Congestion and Reliability: Linking Solutions to Problems, Report for the Federal Highway Administration, Washington DC.

- Dept for Transport (2006) Focus on Freight, London

- Dept for Transport (2007) Congestion on the Strategic Road Network, London

- Freight Best Practice Programme (2007) Various transport KPI report available at www.freightbestpractice.org.uk

- Kuipers, B. and Rozemeijer, S. (2006), Strategies by Shippers and Transport Companies in Response of Decreasing Reliability of Travel Times, TNO, Delft.

- McKinnon, A.C. (1999) 'The effect of traffic congestion on the efficiency of logistical operations' Inter. Journal of Logistics: Research and Applications, Vol. 2, No. 2.

- McKinnon, A.C. and Ge, Y. (2004) 'Use of a synchronised vehicle audit to determine opportunities for improving transport efficiency in a supply chain' Inter. Journal of Logistics: Research and Applications, vol. 7, no.3, 2004, pp 219-238.

- Sankaran, J., Gore, A. and Coldwell, B. (2005) 'The impact of road traffic congestion on supply chains: insights from Auckland, New Zealand.' Inter. Journal of Logistics: Research and Applications Vol. 8, No. 2.

- Wilson, M.C. (2007), 'The impact of transportation disruptions on supply chain performance', Transportation Research Part E, Vol.43, pp.295-320.

- Winston C. and Shirley C. (2004) The Impact of Congestion on Shippers' Inventory Costs, Federal Highway Administration, Washington DC. 